\title{
FUNCTIONAL ENDOSCOPIC SINUS SURGERY
}

\author{
Ahmed M Al-Abbasi ${ }^{*}$, Sabah A Al-Uraibi ${ }^{\circledR}$, \& Saddam S Atshan ${ }^{\#}$ \\ *MB,ChB, FIBMS, FRCS, Professor of ORL-H\&N Surgery, Department of Surgery, College of \\ Medicine, University of Basrah. ${ }^{\circledR} \mathrm{MB}, \mathrm{ChB}$, FIBMS Specialist in ORL-H\&N Surgery, Al Shifaa General \\ Hospital, Basrah. "MB,ChB, DLO Specialist in ORL-H\&N Surgery, Al-Habbobi General Hospital, \\ Nassiriyah, IRAQ.
}

\begin{abstract}
Treatment of sinonasal diseases is either conservative or surgical. The recent advances in surgical management is the use of endoscopic sinus surgery (ESS) as it causes less morbidity, complication, pain and above all, less recurrence rates.

This study aimed to evaluate the effectiveness of ESS for the treatment of nasal \& paranasal sinus diseases and to address the postoperative complications.

A prospective study was done at the Department of Otolaryngology in Basrah Teaching Hospital in the period from January 2016 to August 2019. One hundred twenty six patients with sinonasal diseases were involved in this study, more than this number of patients was operated upon but they either refused participation in this study or dropped from follow-up.

The main indications of surgery were; chronic rhinosinusitis without nasal polyp (33\%), chronic rhinosinusitis with nasal polyp (28.6\%), Allergic fungal sinusitis \& mycetoma (17.4\%), and acute recurrent sinusitis $(16 \%)$.

Main presenting symptoms were; nasal obstruction (85.7\%), nasal discharge (69\%), headache and facial pain $(66.6 \%)$ and hyposmia and or anosmia $(57.9 \%)$.

The majority of operated upon patients were primary cases (98 patients, $77.7 \%$ ), while (28 patients, $22.2 \%$ ) were revision cases. The commonest causes of revision were; retained or incompletely removed uncinate process in $28.5 \%$ of cases, followed by incomplete removal or persistence of anterior ethmoid cells in $21.4 \%$ cases.

In this series complications occurred in 15\%, which were generally minor (9.5\%), major complications occurred in $5.5 \%$ of operated upon patients. The commonest major complication is sever bleeding which was reported in $4.7 \%$ and anosmia which was reported in one patient. No CSF leak, retro orbital haemorrhage, or blindness was reported.

Most of the patients in this series were improved (88.8\%), complete symptom improvement occurred in (75 patients, $59.5 \%$ ), partial improvement (37 patients, $29.3 \%$ ), while (14 patients, $11 \%$ ) were not improved.

In conclusion, functional endoscopic sinus surgery is a safe surgery for sinonasal diseases, it carry good success rate with non-significant major complications.

Key words: Nasal Sinus, Functional Surgery, Endoscopy
\end{abstract}

\section{Introduction}

耳ndoscopic sinus surgery (ESS) is a Crecent addition in the management of chronic sinusitis. Surgical treatment of chronic sinusitis, until late, has been based on the concept that diseased sinus mucosa should be radically removed to enable new healthy mucosa to grow in its place for which most popular operation in the past has been Caldwell-Luc procedure. Messerklinger's work on sinus mucosa and mucociliary transport has now shown that pathology is not primarily in larger sinuses, but is always secondary to impaired drainage caused by the disease in the ethmoidal air cells blocking their natural ostia in the middle meatus 1,2 .

It has now been clearly established that if the ostium of the unhealthy sinus is unblocked surgically by removal of diseased ethmoidal air cells, the rest of the diseased mucosa reverts back to 
normal. Functional endoscopic sinus surgery is a set of minimally invasive surgical techniques which permit direct visual examination and opening of the sinuses for the treatment of chronic rhinosinusitis which has not improved by medical treatment, ${ }^{3,4}$ The use of FESS allows for a much less invasive and traumatic surgery, consequent in shorter surgery and healing times, less postoperative awkwardness, and littler surgical complications.

Rhinosinusitis is inflammation of the mucosal membrane lining the nasal cavities and the paranasal sinuses. Rhinosinusitis lasting more than 12 weeks is classified as chronic rhinosinusitis $(\mathrm{CRS})^{5,6}$.

The aims of treating CRS are to remove underlying causes, diminish sinus inflammation, and drain nasal passages. Medical treatment is the first-line treatment for CRS. Treatment options may include nasal saline sprays, nasal lavage, antibiotic therapy, nasal corticosteroids, oral or injected corticosteroids, decongestants, over-thecounter pain relievers, leukotriene modifiers, and antihistamines. Patients who do not respond to medical therapy are candidates for sinus surgery ${ }^{7}$.

The aim of present study is to evaluate the effectiveness of FESS for the treatment of nose \& paranasal sinus diseases, and to address the postoperative complications.

\section{Patients and Methods}

This prospective study was performed at Department of Otorhinolaryngology in Basrah Teaching Hospital, in the period from January 2016 to August 2019. The study included one hundred twenty six patients who were clinically, endoscopically and radiologically suggestive to have sinonasal diseases and not responded to usual medical treatment.
Malignant diseases of nose and paranasal sinuses were excluded. Preoperative CT of sinus and nasendoscopy serves as a road map for surgery. Surgery was performed usually under general anesthesia except in 5 patients (2 pregnant women in first trimester and 3 patients with uncontrolled DM, and hypertension). Patients were put in supine position with elevation of head. After proper nasal mucosal decongestion, the $0 \mathrm{o}$ and $30 \mathrm{o}$ endoscopes were commonly used along with special Blakesly straight and angled forceps. Following the Ist pass (examination of nasopharynx and inferior meatus), the scope was moved medial to middle turbinate to see sphenoethmoidal recess, opening of posterior ethmoids and sphenoidal sinus (second pass). Third pass, when endoscope was passed into middle meatus to see OMC also called key area.

Uncinate process, ethmoidal bulla, hiatus semilunaris and frontal recess were visualized, uncinectomy was done to visualize the opening of maxillary sinus, ethmoidal bulla if enlarged is also removed by opening at its medial and inferior portion with a Blakesley's forceps.

Posterior ethmoidectomy was done by identifying the ground lamella posterior to the bulla, which was pierced by a upcutting forceps, any other pathology was also dealt likewise, merocele pack was kept to be removed after 24 hours ${ }^{8,9}$, then patients were followed-up for 6 months.

\section{Results}

The study included 126 patients, 71 of them were males and 55 were females, male to female ratio was $1.29: 1$, their age ranged from 9 to 74 years, the commonest operated upon age group was 41-50 years, this is clearly demonstrated in table I. 
Table I: Demographic characteristics of the studied patients.

\begin{tabular}{|c|c|c|c|c|}
\hline Age group & \begin{tabular}{|l|} 
Males \\
\end{tabular} & Femals & Total no. & $\%$ \\
\hline $11-20$ & 4 & 10 & 14 & 11 \\
\hline $21-30$ & 9 & 14 & 23 & \begin{tabular}{|l|}
18.2 \\
\end{tabular} \\
\hline $31-40$ & 13 & 9 & 22 & \begin{tabular}{|l|}
17.4 \\
\end{tabular} \\
\hline $41-50$ & 19 & 9 & 28 & 22.2 \\
\hline $51-60$ & 13 & 8 & 21 & 16.6 \\
\hline 61-70 & 11 & 5 & 16 & \begin{tabular}{|l|}
12.6 \\
\end{tabular} \\
\hline $70-$ & 2 & 0 & 2 & 1.5 \\
\hline Total & 71 & 55 & 126 & 100 \\
\hline
\end{tabular}

Table II, shows the presenting symptoms of the studied patients, the commonest symptom was nasal obstruction, congestion or blockage $(85.7 \%)$, followed by nasal discharge, headache and facial pain $(69 \%$ and $66.6 \%)$ respectively.

Table II: The presenting symptoms of included patients.

\begin{tabular}{|c|c|c|}
\hline Presenting symptom & No. & $\%$ \\
\hline Nasal obstruction (congestion and block) & 108 & 85.7 \\
\hline Nasal discharge & 87 & 69 \\
\hline Headache and Facial pain & 84 & 66.6 \\
\hline Hyposmia and anosmia & 73 & 57.9 \\
\hline Voice changes & 41 & 32.5 \\
\hline Snoring & 36 & 28.5 \\
\hline Nosebleed & 12 & 9 \\
\hline Sigificant sneezing & 8 & 6 \\
\hline
\end{tabular}

The commonest indication of FESS in the present series was chronic rhinosinusitis (78 patients, $61.6 \%$ ) of the studied patients, 42 patients have rhinosinusitis without nasal polyps, while 36 have chronic rhinosinusitis with nasal polyps, as shown in table III.

Table III: Indications of functional endoscopic sinus surgery

\begin{tabular}{||l||l||l||}
\hline Indications of FESS & No. & $\%$ \\
\hline \hline - Chronic rhinosinusitis without nasal polyp & 42 & 33 \\
\hline - Chronic rhinosinusitis with nasal polyp & 36 & 28.6 \\
\hline - Allergic fungal sinusitis and mycetoma & 22 & 17.4 \\
\hline - Acute recurrent rhinosinusitis & 8 & 6.3 \\
\hline - Inverted papillomas & 5 & 3.9 \\
\hline - Frontoethmoidal mucoceles & 4 & 3 \\
\hline - Removal of foreign body in maxillary sinus. & 4 & 3 \\
\hline - Antrochoanal polyp & 3 & 2.3 \\
\hline . Drainage of periorbital abscess & 2 & 1.5 \\
\hline \hline
\end{tabular}


The majority of the patients were operated upon for the first time (primary cases), which involved 98 patients that equal to $(77.7 \%)$, while revision surgery was performed for 28 patients $(22.2 \%)$, this is clearly illustrated in figure 1 .

Figure (1) Primary and revision cases

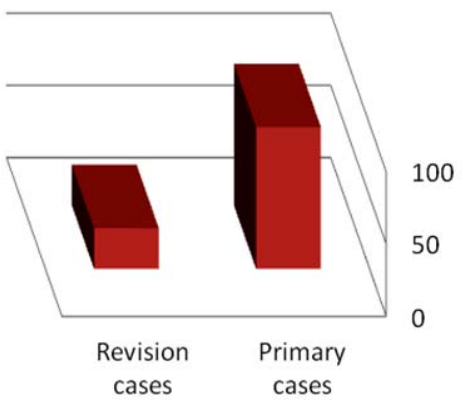

Table IV, display the main causes of revision surgery, the commonest cause was recurrent nasal polyposis which comprised $28.5 \%$, followed by persistent anterior ethmoid cells $(21.4 \%)$.

Table IV: Causes of revision surgery.

\begin{tabular}{|c|c|c|}
\hline Causes of revision surgery & No. & $\%$ \\
\hline \begin{tabular}{|l} 
- Recurrent nasal polyposis \\
\end{tabular} & 8 & 28.5 \\
\hline - Persistant Anterior ethmoidal & 6 & 21.4 \\
\hline - lateralization of remnant of middle turbinate & 4 & 14.3 \\
\hline - Recurrent allergic fungal rhinosinusitis & 4 & 14.3 \\
\hline - Persistant agger nasi cells & 3 & 10.7 \\
\hline - Persistant/recurrent frontal sinus disease & 3 & 10.7 \\
\hline
\end{tabular}

Figure 2, shows the results of FESS performed for the studied patients, the majority (112 patients, more than 88\%) were improved, in 59.5\% (75 patients), the recovery was complete and $29.3 \%$ (37 patients), was partial, while 14 patients $(11 \%)$, there was no improvement.

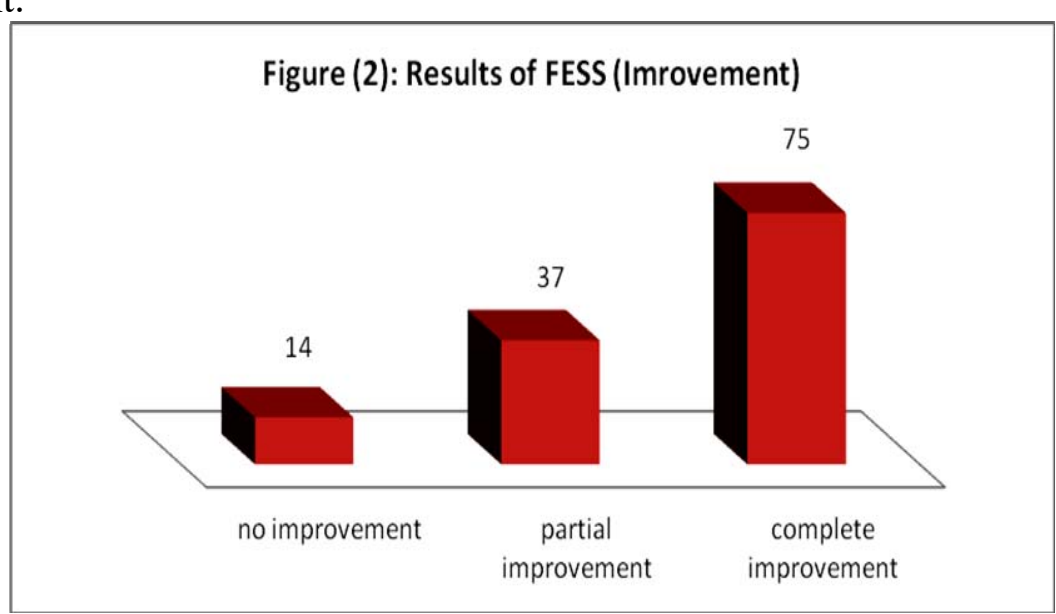


The complications of FESS occurred in 19 patients (15\%). The majority were minors (12 patients, 9.5\%), most of them were synechia, while in 7 patients $(5.5 \%)$, the complications were majors and common major complications were severe intraoperative and postoperative bleeding, this is shown in table V.

Table V: Complications of FESS.

\begin{tabular}{||l||l||l||}
\hline Major Complications & No. & $\%$ \\
\hline \hline Bleeding & 6 & 4.7 \\
\hline Intraoperative & 4 & 3 \\
\hline Postoperative & 2 & 1.5 \\
\hline Anosmia & 1 & 0.7 \\
\hline \hline Minor Complications & No. & $\%$ \\
\hline Synechia & 7 & 5.5 \\
\hline Dental pain and parasthesia & 3 & 2.3 \\
\hline Stenosis of maxillary sinus ostium & 2 & 1.5 \\
\hline
\end{tabular}

\section{Discussion}

The age of this study participants was between 9-74 years while in many studies $^{10-13}$ it was 35.7 to 43.2 years, and 54.0 years in one study ${ }^{11}$.

Males were 71 and females were 55. The gender distribution reported in other studies ${ }^{10-13}$ was males proportion ranging from 54 to $67 \%$, these results are nearly comparable with the present study.

In Shahbaz ${ }^{14}$ study, fifty patients from all age groups i.e., 6-65 years were studied and treated endoscopically. Out of 50 cases 13 were females and 37 were males, this finding is nearly similar to ours.

The commonest indication of FESS in the present series was chronic rhinosinusitis (78 patients, $61.6 \%$ ) of the studied patients, 42 patients have rhinosinusitis without nasal polyps, while 36 were have chronic rhinosinusitis with nasal polyps, this is goes with Dale $\mathrm{H}$. Rice report, he stated that the two basic indications for FESS, are chronic bacterial sinusitis and recurrent bacterial sinusitis ${ }^{15}$. Absolute indications for sinus surgery include bilateral extensive and massive obstructive nasal polyposis with complications and relative indications for sinus surgery include persistent chronic adult rhinosinusitis in spite of aggressive medical therapy ${ }^{16}$.
In the present study, the majority of patients operated upon were for the first time (primary cases), which involved 98 patients that equal to $77.7 \%$, while revision surgery was performed for 28 patients $(22.2 \%)$. In 17 out of $28(60.7 \%)$ a nonendoscopic procedures were performed and $11(39.2 \%)$ patient were by endoscopy. The main causes were recurrent nasal polyposis which comprised $28.5 \%$, followed by persistent anterior ethmoid cells $21.4 \%$.

As with all surgical interventions, the aim of FESS should provide appropriate resolution of pathology without recurrence of disease. Despite this admirable aim, the reality is that up to $20 \%$ of patients will require revision FESS within 5 years, $43 \%$ of which will be within the first postoperative year ${ }^{17}$. A lack of anatomical and physiological understanding can increase the need for revision surgery ${ }^{18}$. Risk factors for requirement of revision surgery are listed below ${ }^{19-22}$. Both the surgeon and patient should be aware that revision FESS carries an increased overall risk of complications and need for further revision surgery ${ }^{23-25}$. The following are risk factors for requiring revision $\mathrm{FESS}^{26}$ : Nasal polyposis, Inverted Papilloma, 
Allergic fungal rhinosinusitis, Frontal sinus disease, Cystic fibrosis, Obesity, Immune deficiency, Smoking, and Female gender.

In the current study, the revision surgeries performed for those who did FESS is only $8 \%$ (11 out of 126 ), which is nearly equal or below these studies which stated that majority of patients undergoing FESS will require a single operation, $10-19 \%$ of patients will require revision surgery ${ }^{27-29}$.

In the current study, the commonest symptom was nasal obstruction, congestion or blockage (85.7\%), followed by nasal discharge, headache and facial pain $(69 \%$ and $66.6 \%)$ respectively, this in agreement with Shahbaz et al study, but not comparable with a study performed for 250 patients in which they found that majority of symptoms were nasal discharge and sinogenic pain (128 and 91) respectively ${ }^{30}$.

The majority of patients underwent FESS in our study. More than $88 \%$ were improved, in $59.5 \%$, the recovery was complete and $29.3 \%$ was partial improvement, while 14 patients (11\%), there was no improvement, this result is better than many studies which recorded that improvement is more than $75 \%{ }^{31,32}$, probably the cause behind that is the short followup period in the present study, but it is much less than a study performed for 120 patients as they found that $97.5 \%$ of patients noted improvement of their complaints $(85 \%$, marked improvement; $12.5 \%$ mild improvement $)^{33}$.

In 2003, a review of the literature by Lieu and Piccirillo ${ }^{34}$ revealed 35 studies that showed improvement of symptoms after FESS ranging from 69 to $94 \%$.

Shahbaz found that FESS with one year followup, resulted in improvement of nasal obstruction $92 \%$, rhinorhea $88 \%$, post nasal drip $88 \%$ and snoring $90 \%$. The complications of FESS in the present study occurred in 19 patients $(15 \%)$. The majority were minors (12 patients, $9.5 \%$ ), mainly were synechia, while in 7 patients $(5.5 \%)$, the complications were majors and common major complications were severe intraoperative and postoperative bleeding.

A study performed in U.K. showed that FESS major complication rate was $0.23 \%$. Cerebrospinal fluid leak was the most common serious complication accounting for 24 of the 36 reports ${ }^{35}$.

Dalziel et $\mathrm{al}^{36}$, found the complication rates be less than $1 \%$. He stated that causes for decrement include improved training and instrumentation.

Complication rates have been reduced as training, experience, comfort with endoscopes and powered instruments have increased. In experienced hands, minor complication rates of $5 \%$ and major complication rates below $1 \%$ were cited $^{37-39}$.

Lieu and Piccirillo ${ }^{40}$ identified 35 articles pertaining to the use of sinus surgery for CRS, with patient improvement associated with FESS ranging from $68.9 \%$ for good outcome ${ }^{41}$ to $94 \%$ with at least $50 \%$ improvement ${ }^{42}$.

Conclusion: Functional endoscopic sinus surgery (FESS) is a minimally invasive surgical procedure which allow direct thorough visual examination and reopening of the sinuses for the treatment of set of sinonasal diseases, which has not responded to medical treatment. The use of FESS permits for a much less aggressive and traumatic procedure, resulting in shorter time for surgery and healing process, with very good improvement, less postoperative awkwardness, and relatively fewer surgical complications. 


\section{References}

1-Hosemann W, Draf C. Danger points, complications and medicolegal aspects in endoscopic sinus surgery. GMS Curr Top Otorhinolaryngol Head Neck Surg. 2013;12:Doc06.

2-Ehnhage A, Olsson P, Kölbeck KG, et al.; NAFS Study Group. Functional endoscopic sinus surgery improved asthma symptoms as well as PEFR and olfaction in patients with nasal polyposis. Allergy. 2009 May;64(5):762-9.

3-Higgins TS, Thorp B, Rawlings BA, et al. Outcome results of endoscopic vs craniofacial resection of sinonasal malignancies: a systematic review and pooled-data analysis. Int Forum Allergy Rhinol. 2011 Jul-Aug;1(4):255-61.

4- Humayun MP, Alam MM, Ahmed S, et al. Comparative study of outcome of the endoscopic sinus surgery and conventional surgery for nasal polyposis. Mymensingh Med J. 2013 Jan;22(1):84-92.

5-Rosenfeld M. Richard. Otolaryngology Head and Neck Surgery. 2015 April ;152(4):598-609.

6-Peters AT, Spector S, Hsu J, et al. Diagnosis and management of rhinosinusitis: a practice parameter update. Ann Allergy Asthma Immunol. 2014 Oct;113(4):347-85.

7- Benninger, M. et al. Adult Chronic Rhinosinusitis: Definitions, Diagnosis, Epidemiology, and Pathophysiolog. Otolaryngology Head Neck Surg 2003; 129S: S1-S32

8-Amber Luong ,Bradley F. Marple. Sinus Surgery Indications and Techniques. Clinical Reviews in Allergy \& Immunology . 2006 Volume 30.

9-B. S. Tuli, Functional endoscopic sinus surgery, Textbook of EAR, NOSE AND THROAT, second edition Jaypee Brothers Medical Publishers (P) Ltd (2013) pp.464-467.

10-Miller RS, Steward DL, Tami TA, Sillars MJ, Seiden AM, Shete M, Paskowski C, Welge J .The clinical effects of hyaluronic acid ester nasal dressing (Merogel) on intranasal wound healing after functional endoscopic sinus surgery. Otolaryngol Head Neck Surg 2003;128:862-869

11. Shoman N, Gheriani H, Flamer D, Javer A. Prospective, double-blind, randomized trial evaluating patient satisfaction, bleeding, and wound healing using biodegradable synthetic polyurethane foam (NasoPore) as a middle meatal spacer in functional endoscopic sinus surgery. J Otolaryngol Head NeckSurg. 2009; 38:112-118

12. Szczygielski K, Rapiejko P, Wojdas A, Jurkiewicz D. Use of CMC foam sinus dressing in FESS. Eur Arch Otorhinolaryngol 2010;267:537-540

13. Cho KS, Shin SK, Lee JH, Kim JY, Koo SK, Kim YW, Kim MJ, Roh HJ The efficacy of Cutanplast nasal packing after endoscopic sinus surgery: a prospective, randomized, controlled trial. Laryngoscope. 2011;123:564-56

14- Shahbaz Mujtaba Ghori, Bacht Aziz, Abid Rashid, Mansoor Basir Pal. An Analysis of Functional Endoscopic Sinus Surgery (FESS) for Sinonasal Disease. P J M H S. 2012 vol 6 no.4 Oct - Dec

15- Dale H. Rice, Indications for Endoscopic Sinus Surgery, ENT Journal · July 1994. Volume 73, Number 7

16- Sclafani AP, Schaefer SD. Triological thesis: concurrent endoscopic sinus surgery and cosmetic rhinoplasty: rationale, risks, rewards, and reality. Laryngoscope. 2009;119:778

17- Stein NR, Jafari A, DeConde AS. Revision rates and time to revision following endoscopic sinus surgery: a large database analysis. Laryngoscope. $2018 ; 128: 31$

18- Bewick J, Egro FM, Masterson L, Javer AR, Philpott CM. Anatomic findings in revision endoscopic sinus surgery: case series and review of contributory factors. Allergy Rhinol (Providence). 2016;7:e151-7.

19- This study shows that patients with nasal polyps are more likely to require revision surgery than those without polyps. 6. Mendelsohn D, Jeremic G, Wright ED, Rotenberg BW. Revision rates after endoscopic sinus surgery: a recurrence analysis. Ann Otol Rhinol Laryngol. 2011;120:162-6

20- Suzuki S, Yasunaga H, Matsui H, Fushimi K, Kondo K, Yamasoba T. Complication rates after functional endoscopic sinus surgery: analysis of 50,734 Japanese patients. Laryngoscope. 2015;125: 1785-91.

21- Philpott C, Hopkins C, Erskine S, Kumar N, Robertson A, Farboud A, et al. The burden of revision sinonasal surgery in the UK-data from the Chronic Rhinosinusitis Epidemiology Study (CRES): a cross-sectional study. BMJ Open. 2015;5:e006680.

22- Wu AW, Ting JY, Platt MP, Tierney HT, Metson R. Factors affecting time to revision sinus surgery for nasal polyps: a 25 -year experience. Laryngoscope. 2014;124:29-33.

23- Fokkens WJ, Lund VJ, Mullol J, Bachert C, Alobid I, Baroody F, et al. European position paper on rhinosinusitis and nasal polyps 2012. Rhinol Suppl. 2012;23:3 p preceding table of contents: $1-298$

24- Masterson L, Tanweer F, Bueser T, Leong P. Extensive endoscopic sinus surgery: does this reduce the revision rate for nasal polyposis? Eur Arch Otorhinolaryngol. 2010;267:1557-61.

25- Krings JG, Kallogjeri D, Wineland A, Nepple KG, Piccirillo JF, Getz AE. Complications of primary and revision functional endoscopic sinus surgery for chronic rhinosinusitis. Laryngoscope. 2014;124:838-45.

26- Managing Complications and Revisions in Sinus Surgery A. Khanna1 \& A. Sama2 . Current Otorhinolaryngology Reports (2019) 7:79-86 https://doi.org/10.1007/s40136-019-00231-3)

27-Stein NR, Jafari A, DeConde AS. Revision rates and time to revision following endoscopic sinus surgery: a large database analysis. Laryngoscope. 2018;128:31

28-This study shows that patients with nasal polyps are more likely to require revision surgery than those without polyps. 6. Mendelsohn D, Jeremic G, Wright ED, Rotenberg BW. Revision rates after endoscopic sinus surgery: a recurrence analysis. Ann Otol Rhinol Laryngol. 2011;120:162-6.

29-Hopkins C, Slack R, Lund V, Brown P, Copley L, Browne J. Longterm outcomes from the English national comparative audit of surgery for nasal polyposis and chronic rhinosinusitis. Laryngoscope. 2009;119:2459-65.

30- Howard Levin. Functional endoscopic sinus surgery: Evaluation, surgery and follow up of 250 patients.Laryngoscope100, January 1990. 79-84 31- Bhattacharyya N. Symptom outcomes after endoscopic sinus surgery for chronic rhinosinusitis. Arch Otolaryngol Head Neck Surg 2004;130(3):329-333. Crossref, Medline, Google Scholar

32-Smith TL, Litvack JR, Hwang PH et al. Determinants of outcomes of sinus surgery: a multi-institutional prospective cohort study. Otolaryngol Head Neck Surg 2010;142(1):55-63. Crossref, Medline, Google Scholar

33-. Kennedy D: Prognostic factors, outcomes and staging in ethmoid sinus surgery. Laryngoscope 1992, 102:1-18.

34- Lieu, J.E. and Piccirillo, J.F. (2003), Arch Otolaryngol Head Neck Surg 129, 1230-1235

35-Clinical Otolaryngology \& Allied Sciences Volume 19, Issue 3 Major complications of functional endoscopic sinus surgery V. L. CUMBERWORTH R. M. SUDDERICK I. S. MACKAYJune 1994

36. Dalziel K, Stein K, Round A, et al.: Systematic review of endoscopic sinus surgery for nasal polyps. Health Technol Assess 2003, 7:iii, 1-159 37-Hosemann W, Draf C. Danger points, complications and medicolegal aspects in endoscopic sinus surgery. GMS Curr Top Otorhinolaryngol Head Neck Surg. 2013;12:Doc06

38- Hopkins C, Browne JP, Slack R, Lund VJ, Topham J, Reeves BC, et al. Complications of surgery for nasal polyposis and chronic rhinosinusitis: the results of a national audit in England and Wales. Laryngoscope. 2006;116:1494-9.

39- Chou T-W, Chen P-S, Lin H-C, Lee K-S, Tsai H-T, Lee J-C, et al. Multiple analyses of factors related to complications in endoscopic sinus surgery. J. Chin. Med. Assoc. 2016;79:88-92. This study shows that there is no increase in complication rates with the use of the microdebrider. 40-Piccirillo JF, Payne SC, Rosenfeld RM, et al. Clinical consensus statement: balloon dilation of the sinuses. Otolaryngol Head Neck Surg. 2018 Feb;158(2):203-214

41-Sharp HR, Rowe-Jones JM, Mackay IS: The outcome of endoscopic sinus surgery: correlation with computerized tomography score and systemic disease. Clin Otolaryngol 1999, 24:39-42.

42- Marks SC, Shamsa F: Evaluation of prognostic factors in endoscopic sinus surgery in sinusitis. Am J Rhinol 1997, 11:187-191. 